\title{
CURRENT ISSUES IN DECISION MAKING FOR OTHERS
}

\author{
Sascha Füllbrunn ${ }^{1}$, Wolfgang Luhann ${ }^{2}$, and Alan Sanfey ${ }^{3}$
}

\section{INTRODUCTION}

A vast array of important decisions in life are made on behalf of others; parents decide for their children, politicians on behalf of their voters, the CEO in the interests of the company, or more generally, the trustee for the beneficiary. This special issue covers topics, methods and, most importantly, results pertaining to decisions that are taken on behalf of others. To date, economic decision theory remains largely silent on the processes underlying decisions made for others. Several theories aim to explain individual decision-making in economic situations by invoking the pure aim of maximizing one's personal (utility) function that reflects the preferences of the individual, without integrating any preference ascribed to the utility of others. Other theories describe interrelated utility functions that do take into account the others' welfare, which can be summarized as invoking 'otherregarding preferences', that is, awareness of differences in payoffs between the decision maker (DM) and others (e.g. Bolton and Ockenfels, 2000; Fehr and Schmidt, 1999; Rabin, 1993; Dufwenberg and Kirchsteiger, 2006). Most notable are the concepts of inequality aversion, fairness, and reciprocity. However, these concepts do not take the others' preferences into account per se, but instead only the DM's relative standing towards the others' well-being and, in some cases, the others' intentions. The application of these is therefore mostly limited to a certain fractional aspect of the DM's motivations when choosing for others, namely the relative positions of the involved parties' post-decision outcomes. Further theories specify contracts that aim to align the DM's incentives with the others' preferences. These 'principal-agent theories' (e.g., Bernheim and Whinston, 1986; Hart and Holmström, 1987; Holmström and Milgrom, 1991) usually operate in situations where asymmetric information can lead to moral hazard. The contract links the DM's payoff to the action outcome such that the others' preferences regarding the outcome are met. But again, the utility of the others is not directly included into the DM's choice in these models; the contract ensures the acknowledgement of these preferences on the DM. Currently therefore, there does not seem to be a (widely accepted) theoretical framework that explicitly includes the preferences of others as a key factor for the DM themselves.

When a DM takes, for example, a risky decision for another, which does not affect her/his own payoff, what would the decision be? Economic theory makes no predictions in the absence of incentives for the DM. What about psychology? Some studies in this domain borrow related aspects from prospect theory concluding from behavioural patterns observed in experiments that there is an attenuation of

\footnotetext{
1 Institute for Management Research, Radboud University, Nijmegen, The Netherlands. Contact: s.fullbrunn@fm.ru.nl

${ }^{2}$ University of Portsmouth, Faculty of Business and Law, Richmond Building, Portland Street, Portsmouth PO1 3DE, United Kingdom. Contact: wolfgang.luhan@port.ac.uk

3 Behavioural Science Institute, Radboud University Nijmegen, PO Box 9104, 6500 HE Nijmegen, the Netherlands. Donders Institute for Brain, Cognition and Behaviour, Radboud University, PO Box 9101, 6500 HB Nijmegen, the Netherlands
} 
the fourfold pattern of risk (e.g., Pahlke, Strasser, and Vieider, 2015; Tversky and Kahnemann, 1992). The key concept here is the presence of 'psychological distance' between a decision made for self (dmfs) and a decision made for others (dmfo). For example, under dmfs the DM might have a particular loss aversion parameter $\lambda_{d m f s}=2.8$ but under dmfo, loss aversion is less severe - as the risk affects another person - and might become $\lambda_{d m f o}=1.3$, thus increasing risk taking for others (e.g. Füllbrunn and Luhan, 2018). Hence, the decision environment changes the perspective of the $\mathrm{DM}$, but the difference is a psychological effect within the person, e.g. due to a reduction in emotions, regret, or perception of payments when making decisions for others.

However, when uncertainty about states of the world come into play current theories of risky decision making for others are sometimes in conflict which each other; psychology suggests that people take more risk with other people's money due to differences in the perception and value of possible outcomes. Beisswanger et al (2003), for example, report that potential negative outcomes of risky decisions play a larger role in decisions for one self than for others, which in part explains the observed reduction in loss aversion in dmfo (e.g. Füllbrunn and Luhan, 2018). In contrast, the theory of social responsibility predicts more conservative approaches to decisions taken for others, with lower levels of risk taking and even a higher level of effort due to a feeling of responsibility (Bolton, Ockenfels, and Stauf, 2015; Charness, 2000; Charness and Jackson, 2009).

This lack of a consistent theory has encouraged researchers in both economics and psychology to undertake experiments in search of a general pattern for the unique motivating factors in dmfo that could eventually lead to the construction of a comprehensive theory. In particular, in the last couple of years more than 70 papers across disciplines have been published to explore the special case of decisions for others (the results are not consistent though, see Polman and $\mathrm{Wu}$, this issue.), and this issue is the fruits of much of this work.

Having being interested in this important topic for several years, we (Wolfgang and Sascha) suggested the special issue on dmfo to this journal as we were already planning a workshop on this topic. This took place at Radboud University in Nijmegen, the Netherlands, in July 2018, ${ }^{4}$ and researchers from various disciplines from all over the world joined us. We selected 23 oral presentations and five poster presentations, and had a fruitful, interdisciplinary, scientific discussion with more than 40 participants. Notably, we implemented a new computer-aided brainstorm session to discuss the topic and generate new ideas moderated by Etiënne Rouwette from the Institute of Management Research using meetingsphere, a browser embedded software. First, the participants provided individual and anonymous statements addressing the question "What are the empirical insights we have so far about dmfo?" The approximately 150 statements were categorized in folders, i.e. risk preferences, methodology, time preferences, social preferences, individual characteristics, theory, among others. This first task showed that dmfo as a topic is quite broad and that there is a long list of relevant findings available, though often relating to different, and partly distinct, subquestions. The second question was "What are the questions we would like to answer with dmfo?" Here most of the statements circled around the specific characteristics of the decision-maker and the other, for example their relationship to each other, the decision environment, how to organize a conceptual model of the situation regarding preferences, beliefs, emotions, cognition, and to what extent delegation plays a role. Again, we found that the topic is simply too broad to outline a conceptual model in the short time we had available (though note that Tunney and Ziegler (2015) have already presented a first attempt at such a model). In particular, we found that the link between the psychology of decision making (e.g. in

${ }^{4}$ https://www.ru.nl/nsm/imr/vm/decision-making-others-2018/ 
terms of prospect theory) and the integration of the others' utility into the decision maker's utility (e.g. social preferences) was missing. The promotion of this Special Issue was one additional aim of the workshop, and we were heartened that many participants from this workshop submitted to this special issue.

We received many submissions, and the process of evaluating these has been very exciting. We had additional help from Alan Sanfey, an expert in decision neuroscience, in guest-editing this special issue. We are very grateful to the many researchers who helped us with refereeing, and we are proud of the articles that were accepted for publication. We eventually selected eight articles for publication while the editor's in chief handled the submissions from the guest editors. Hence, we thank Stefan Schulz-Hardt and Martin Kocher for accepting our proposal and for starting the special issue, and Carlos Alós-Ferrer for finalizing it.

\section{CONTENT}

All of the contributors to this special issue endeavour to shed light on the question of how people make decisions for others. However, and usefully, the various articles consider the same question in different environments. Some of these articles analyse how participants take risky decisions for others with equal or unrelated consequences for the decision maker themselves (Füllbrunn and Luhan, this issue; Ertac, Gumren, and Gurdal, this issue; Losecaat Vermeer, Boksem and Sanfey, this issue; Barrafrem and Hausfeld, this issue; Polman and Wu, this issue). The typical questions here is whether we observe a risky shift, i.e. the DM takes higher risks for the others than for themselves, or a cautious shift, i.e. the DM takes lower risks for the others (Stoner, 1961).

In Füllbrunn and Luhan (this issue), the DM takes substantial responsibility in an investment decision (Gneezy and Potters, 1997) for six other subjects. The authors show that subjects invest significantly less for others than for themselves - independent of whether the DM face no payoff consequences or similar consequences as the six others - which is mainly driven by the relatively risk seeking subjects. However, as soon as the DM earns a tiny fraction of the profits with no consequences for losses (privatizing gains, socializing losses) the investment levels increase significantly to almost twice the level observed before. While dmfo generally seems to be driven by a trade-off between egoistic and social preferences, such convex incentives clearly trigger egoistic preferences while repelling social preferences. The experimental design of the limited liability treatment is a new environment to study situations in which DM take social risks for own benefits.

Ertac, Gumren, and Gurdal (this issue) consider the 'demand for authority' and the 'demand for autonomy'. In the experimental setting, a DM takes a risky decision for themselves and another subject, again using an investment game (Gneezy and Potters, 1997). Before this investment decision, the authors elicit the DM's willingness to pay to avoid making the risky decision for the other subject. At the same time they also elicit the other's willingness to pay to make the decisions themselves and not having the DM decide for them. Overall, Ertac, Gumren, and Gurdal (this issue) find that the others are willing to pay extra for taking their own decision while the DMs are not willing to pay extra for avoiding responsibility. The authors find several individual characteristics to affect delegation and decision making for others, most notably that males are willing to pay for their autonomy and that other-regarding preferences lead to avoidance of decisions for others involving losses.

Barrafrem and Hausfeld (this issue) study information processing in dmfo and dmfs situations using eye-tracking methodology. Using the Hey and Orme (1994) lottery selection design, they find no difference between dmfs and dmfo using structural estimations in a Cumulative Prospect Theory framework under different decision conditions based on dual process theory (control, deliberation, intuition). However, at the information processing level they find DMs to have higher error rates when 
making decisions for others, i.e. choices are less consistent, which leads the authors to the conclusion that DMs spend less effort when deciding for others.

Losecaat Vermeer, Boksem and Sanfey (this issue) use a different risk-taking scenario to analyse the difference between dmfo and dmfs. In their experiment, subjects experience either a gain or a loss, and subsequently can choose an additional mixed lottery to either get even after a loss, or to double their earnings after a gain. In line with prospect theory, the loss environment triggers risk seeking behaviour while the gain environment triggers risk aversion, and this result holds independent of whether they consider dmfo or dmfs. However, under dmfo the DM is more likely to accept the risk after a gain (risky shift in the gain domain). Overall, they observe a reduced impact of gains and losses under dmfo and discuss their results in terms of reduced salience and subjective value for prior gain/loss contexts, and consequently reduced engagement of affective processes.

Polman and Wu (this issue) finally summarize the (to the best of our, and their knowledge) entire existing literature on dmfo regarding decisions under risk. In their meta study they consider 71 reports with 128 effects and a total of 14,443 observations. They find a small effect size in favour of a risky shift in dmfo. Digging deeper into the design features - like for whom the decisions are taken, whether a within- or a between-subject design was implemented, or whether decisions were hypothetical or incentivised - they find the sobering result that there is no clear shift. Polman and Wu (this issue) clearly show that it is difficult to integrate isolated experiments into a general framework.

For the articles above, the experimental environments were chosen such that differences in payments between the DM and the other can be (or have been) neglected. The next set of articles incorporate other-regarding preferences, i.e. they take the allocation of outcomes between DM and other(s) into account.

In a systematic analysis of the investment of both the DM and the other in the decision situation, Konow, Saijo, and Akai (this issue) use a dictator game to analyse the effect of several decision factors - most notably the DM's stake in a situation (spectator vs. stakeholder) and their position relative to others (in-group vs. out-group) - on adopted fairness rules. Using participants from two countries (USA and Japan) they find that in spectator decisions, allocations were significantly related to recipient entitlements, suggesting that an equity fairness preference was favoured. Conversely, stakeholder decisions were closer to equality, and in-group decisions were closer still. However, neither were unaffected by entitlement, implying that equity preferences were still employed to some degree. In stark contrast, out-group decisions favoured neither preference, significantly exceeding both equity and equality. This showed that decision makers were self-interestedly biased toward their in-group. These results held, for the most part, across both the US and Japanese sample.

There is a long lasting discussion in the experimental literature whether gender differences in individual risky decisions exist; Friedl, Pondorfer and Schmidt (this issue) concentrate on gender differences in situations with social risk taking. Using an experimental design based on Eckel and Grossman (2002), they consider a design in which the outcomes of the lotteries are either positively correlated ( $P C R$, payments for DM/other in two states of the world are either high/high or low/low) or negatively correlated (NCR, payments for DM/other are either high/low or low/high). More generally they conclude that DMs take conservative risks for others. However, this result is driven by inequality aversion as-in particular females-take less risk for others in NCR than in PCR. Less risk taking in NCR means more equal payments. Examining participants from Papua New Guinea, which is more egalitarian than the typical student subjects (Friedl, Pondorfer and Schmidt, this issue), the effect almost disappears. 
Fonsari, Ploner, and Soraperra (this issue) also observe a form of cautious shift. Using the Columbia Card Task (see, e.g., Figner et al., 2009) the authors analyse whether DMs are willing to spend their own or the other's resources to reduce the risk for either. When given the chance to see the cards reducing the risk - for a cost before the choice, DMs spend more money on reducing the risk for others than for for themselves. However, another important result from their study is that DMs are also willing to spend more of the other's money to reduce risks than of their own, results largely in line with Friedman's (1979) 'four ways to spend money'.

Waichman and von Blanckenburg (this issue) consider a somewhat different approach by taking dmfo to a strategic environment. They implement a Cournot competition game in which DMs chose the amount to produce which determines the prices and thus the revenue of the producer. The authors compare situations where individuals act as firms or where the DM and a passive other are a firm, systematically varying the involvement of the other (silent, can communicate with DM, sitting together but only DM is allowed to act). The authors find that, in principle, the DMs make similar decisions in dmfs and dmfo, which can largely be attributed to the strength of market forces in these types of experiments. The main finding in their paper, however, is that when making decisions for others DMs do not react to clues to collude with other market participants and show higher levels of competitiveness.

The final article takes a holistic approach by comparing dmfo vs dmfs in different games. Ifcher and Zarghamee examine whether a range of different behavioural biases, which have previously been identified in the literature, also apply under dmfo. They use the observations from 18 different tasks to study whether individual decision models and the related deviations found in experiments can explain behaviour in dmfo. The main result found in these various task are that DMs have a higher willingness to pay in dmfo when the tasks involve anchoring, an endowment effect or identifiablevictim bias, and that in dmfo the DMs more often do not display a clear preference structure in the various tasks. The higher willingness to pay is in line with Fonsari, Ploner, and Soraperra (this issue), again showing that the others' budget is less important than our own, when making similar decisions. The latter result points towards psychological self-other distance. It also demonstrates that it is not always clear who the relevant 'other' party is if several people are affected by a decision, e.g., when donating somebody else money to a third party.

\section{CONCLUSION}

This special issue considers dmfo vs dmfs in different experimental games, with different methodologies, and using a variety of experimental designs, which taken together reflect a wide spectrum of economic decision contexts. All of the papers in this issue look at similar aspects, but from quite different angles. While this provides a broad overview of how different approaches tackle the important question of dmfs $v \mathrm{dmfo}$, one challenge is that as a whole the results are perhaps too varied to integrate in a single overarching existing theoretical framework. The reason is that a) an agreed-upon holistic theoretical framework does not yet exist (Tunney and Ziegler, 2015, represent one first attempt) and that $b$ ) the experiments focus on different aspects that are to date not integrated, as they often occur in very different circumstances and represent very different aspects of everyday life. It is also important to note the nature of the differences between these studies - how the experiments are implemented (e.g. laboratory, field, online), what are the incentives (e.g. hypothetical, real), what is the amount of responsibility (e.g. one other, several others), what are the consequences for the decision maker (aligned incentives, fixed incentives, no incentives), for whom is the decision made (stranger, friends), the level of accountability, gain vs. loss domain, and so on. All of these contextual factors have been found to influence the DM, just as do the individual 
characteristics of the DM (e.g. the influence of gender (Friedl, Pondorfer and Schmidt, this issue) or the influence of own risk preferences (Füllbrunn and Luhan, this issue) and the individual characteristics of the others (choices for children vs adults, relative wealth, gender etc.). Finally, researchers consider different theoretical frameworks (see e.g. Polman and $\mathrm{Wu}$, this issue, on theoretical concepts) and form their conclusions based on the various model assumptions. Hence, in our view, currently the literature provides excellent articles with many robust results but many of the findings appear to be difficult to integrate into one consolidating framework. This clearly is the most important task for future research into dmfo.

As often the case, research does not fully answer existing questions but rather creates new ones, and this Special Issue is a clear case of the latter. However, it has also shown us the benefit of bringing together researchers from different disciplines who use different approaches with the goal of learning from each other and contributing towards a fuller understanding of this important topic. To continue this initiative, we would like to in create an active research network with the aim of contributing to the question as to how people make decisions for others. If you are interested in being part of such a network, please provide your details in an email to dmfo.group@gmail.com. We anticipate real progress in this area in the coming years, and welcome your involvement! 


\section{REFERENCES}

Barrafrem, K. \& Hausfeld, J. (this Issue). Tracing risky decisions for oneself and others: The role of intuition and deliberation, Journal of Economic Psychology

Beisswanger, A. H., Stone, E. R., Hupp, J. M., Allgaier, L. (2003). Risk taking in relationships:

Differences in deciding for oneself versus for a friend. Basic and Applied Social Psychology 25 (2), 121-135.

Bernheim, D. B. \& Whinston, M. D. (1986). Common agency. Econometrica: Journal of the Econometric Society, 923-942.

Bolton, G. E., \& Ockenfels, A. (2000). Erc: A theory of equity, reciprocity, and competition. American Economic Review, 90(1), 166-193.

Bolton, G. E., Ockenfels, A., \& Stauf, J. (2015). Social responsibility promotes conservative risk behavior. European Economic Review, 74, 109-127.

Charness, G. (2000). Responsibility and effort in an experimental labor market. Journal of Economic Behavior \& Organization, 42(3), 375-384.

Charness, G., \& Jackson, M. O. (2009). The role of responsibility in strategic risk-taking. Journal of Economic Behavior \& Organization, 69(3), 241-247.

Dufwenberg, M., \& Kirchsteiger, G. (2004). Dufwenberg

.Games and economic behaviour, 47(2), 268-298.

Eckel, C. C., \& Grossman, P. J. (2002). Sex differences and statistical stereotyping in attitudes toward financial risk. Evolution and Human Behavior, 23(4), 281-295.

Ertac, S., Gumren, M., \& Mehmet Y. Gurdal, M. Y. (this Issue). Demand for decision autonomy and the desire to avoid responsibility in risky environments: Experimental evidence, Journal of Economic Psychology

Fehr, E., \& Schmidt, K. M. (1999). A theory of fairness, competition, and cooperation. Quarterly Journal of Economics, 817-868.

Figner, B., Mackinlay, R. J., Wilkening, F., \& Weber, E. U. (2009). Affective and deliberative processes in risky choice: Age differences in risk taking in the Columbia card task. Journal of Experimental Psychology: Learning, Memory, and Cognition, 35(3), 709.

Fornasari, F. Ploner, M., \& Soraperra, I. (this issue). Interpersonal risk assessment and social preferences: An experimental study, Journal of Economic Psychology

Friedl, A., Pondorfer, A., \& Schmidt, U. (this issue). Gender differences in social risk taking, Journal of Economic Psychology

Friedman, M., \& Friedman, R. (1979). Free to choose: A personal statement. Houghton Mifflin Harcourt.

Füllbrunn, S. C., \& Luhan, W. J. (2017). Decision making for others: The case of loss aversion. Economics Letters, 161, 154-156.

Füllbrunn, S. C., \& Luhan, W. J. (this issue). Responsibility and limited liability in decision making for others - An experimental consideration, Journal of Economic Psychology 
Gneezy, U., \& Potters, J. (1997). An experiment on risk taking and evaluation periods. The Quarterly Journal of Economics, 112(2), 631-645.

Hart, O. \& Holmström, B. (1987). The theory of contracts. in Bewley, T. (ed.).Advances in Economics and Econometrics. Cambridge University Press. 71-155.

Hey, J. D., \& Orme, C. (1994). Investigating generalizations of expected utility theory using experimental data. Econometrica, 62, 1291-1326.

Holmström, B., \& Milgrom, P. (1991). Multitask Principal-Agent Analyses: Incentive Contracts, Asset Ownership, and Job Design, Journal of Law, Economics, and Organization, 4, 24-52

Ifcher, J. \& Zarghamee, H. (this issue). Behavioral economic phenomena in decision-making for others, Journal of Economic Psychology

Konow, J., Saijo, T., \& Akai, K. (this issue). Equity versus equality: Spectators, stakeholders and groups, Journal of Economic Psychology

Losecaat Vermeer, A. B., Maarten A. S. Boksem, M.A.S., \& Sanfey, A.G. (this Issue). Third-party decision-making under risk as a function of prior gains and losses, Journal of Economic Psychology (this Issue)

Pahlke, J., Strasser, S., \& Vieider, F. M. (2015). Responsibility effects in decision making under risk. Journal of Risk and Uncertainty, 51(2), 125-146.

Polman, E. \& Wu, K. (this issue). Decision making for others involving risk: A review and metaanalysis, Journal of Economic Psychology

Rabin, M. (1993). Incorporating Fairness into Game Theory and Economics. The American Economic Review, 83(5), 1281-1302

Stoner, J. A. F. (1961). A comparison of individual and group decisions involving risk (Doctoral dissertation, Massachusetts Institute of Technology).

Tunney, R. J., \& Ziegler, F. V. (2015). Toward a psychology of surrogate decision making. Perspectives on Psychological Science, 10(6), 880-885.

Tversky, A., \& Kahneman, D. (1992). Advances in Prospect Theory: Cumulative Representation of Uncertainty. Journal of Risk \& Uncertainty, 5(4), 297-323.

Waichman, I. \& von Blanckenburg, K. (this issue). Is there no "I" in "Team"? interindividualintergroup discontinuity effect in a Cournot competition experiment, Journal of Economic Psychology 